Supporting Information (SI)

\title{
Design of a Bioinert Interface Using an Amphiphilic Block Copolymer Containing a Bottlebrush Unit of Oligo(oxazoline)
}

Jin-Hyeok Hong, ${ }^{\dagger}$ Masayasu Totani, ${ }^{\dagger}$ Daisuke Kawaguchi, ${ }^{\dagger, \dagger}$ Hiroyasu Masunaga, ${ }^{,}$Norifumi L. Yamada, ${ }^{\#}$ Hisao Matsuno, ${ }^{*},+, \neq, \$$ and Keiji Tanaka ${ }^{*},+,+, \$$

† Department of Applied Chemistry, Kyushu University, Fukuoka 819-0395, Japan

${ }^{\ddagger}$ Centre for Polymer Interface and Molecular Adhesion Science, Kyushu University, Fukuoka 819-0395, Japan

" Japan Synchrotron Radiation Research Institute (JASRI), Hyogo 679-5198, Japan

\# High Energy Accelerator Research Organization, Ibaraki 319-1106, Japan

$\S$ International Institute for Carbon-Neutral Energy Research (WPI-I2CNER), Kyushu University, Fukuoka 819-0395, Japan

*To whom correspondence should be addressed

FAX: +81-92-802-2880 TEL: $+81-92-802-2878$

E-mail: h-matsuno@cstf.kyushu-u.ac.jp \& k-tanaka@cstf.kyushu-u.ac.jp 


\section{Polymer Syntheses}

1.1. Materials. 2-ethyl-2-oxazoline (> 98.0\%), ethyl $\alpha$-bromoisobutyrate (EBiB, > 98.0\%), triethylamine (TEA, $>99.0 \%)$, potassium carbonate $\left(\mathrm{K}_{2} \mathrm{CO}_{3},>99.5 \%\right)$, and lithium bromide $(\mathrm{LiBr}$, $>99.0 \%$ ) were purchased from Tokyo Chemical Industry Co., Tokyo, Japan (TCI). Calcium hydride $\left(\mathrm{CaH}_{2},>90.0 \%\right)$ was purchased from NACALAI TESQUE, INC., Kyoto, Japan. Methacrylic acid (MAA, > 99.0\%), $N, N, N^{\prime}, N^{\prime \prime}, N^{\prime \prime}$-pentamethyldiethylenetriamine (PMDETA, > 99.0\%), and chloroform- $d\left(\mathrm{CDCl}_{3},>99 \%, 99.8 \%\right.$ atom D) were purchased from Merck, $\mathrm{KGaA}$, Darmstadt, Germany. Methyl methacrylate (MMA, > 98.0\%), methyl trifluoromethanesulfonate (MeOTf, $>95.0 \%$ ), acetonitrile (> 99.8\%), $N, N$-dimethylformamide (DMF, $>99.5 \%$ ), diethyl ether (> 99.5\%), anisole (> 99\%), and basic alumina (particle size of approximately $75 \mu \mathrm{m}$ ) were purchased from FUJIFILM Wako Pure Chemical Industries Ltd., Osaka, Japan. Copper(I) bromide $(\mathrm{CuBr},>95 \%)$ and methanol (> 99.5\%) were purchased from Kishida Chemical Co. Ltd., Osaka, Japan. Chloroform (> 99.0\%), toluene (> 99.0\%), and hexane (>96.0\%) were purchased from Kanto Chemical Co., Tokyo, Japan.

2-ethyl-2-oxazoline, TEA, MeOTf, and acetonitrile were distilled with $\mathrm{CaH}_{2}$. MAA was purified by distillation under vacuum to remove inhibitors. MMA was purified by passing through a column filled with basic alumina to remove inhibitors. Unless otherwise stated, all chemicals were used as received.

1.2. Characterization. Chemical structures of each polymer were confirmed by ${ }^{1} \mathrm{H}$-nuclear magnetic resonance $\left({ }^{1} \mathrm{H}-\mathrm{NMR}\right)$ spectroscopy using an ECZ-400S spectrometer (JEOL Ltd., Akishima, Tokyo, Japan) at $298 \mathrm{~K} . \mathrm{CDCl}_{3}$ was used as a solvent. Number-average molecular weight $\left(M_{\mathrm{n}}\right)$ and molecular weight distribution $\left(M_{\mathrm{w}} / M_{\mathrm{n}}\right)$ of the polymers, where $M_{\mathrm{w}}$ is a weightaverage molecular weight $\left(M_{\mathrm{w}}\right)$, were examined by size exclusion chromatography (SEC) on an HLC-8120GPC (TOSOH Corp., Tokyo, Japan) equipped with TSKgel Super AW5000 and AW4000 columns packed with a micro-particulate gel based on hydrophilic vinyl polymer (each: $6.0 \mathrm{~mm}$ internal diameter $\times 150 \mathrm{~mm}$ length, TOSOH Corp.). As an eluent, DMF containing 10 $\mathrm{mM}$ of $\mathrm{LiBr}$ and $30 \mathrm{mM}$ of TEA was used at a flow rate of $0.5 \mathrm{~mL} \cdot \mathrm{min}^{-1}$ at $313 \mathrm{~K}$. A calibration curve was prepared using five standards of poly(methyl methacrylate) (PMMA, Merck).

1.3. Macromonomer Synthesis. Methacrylate-terminated macromonomers, oligo(2-ethyl-2oxazoline) methacrylate referred to as $\mathrm{O}(\mathrm{Ox}) \mathrm{MA}$, was synthesized by living cationic ring-open 
polymerization (LCROP) of 2-ethyl-2-oxazoline. ${ }^{\mathrm{S} 1, \mathrm{~S} 2}$ A typical procedure was as follows. MeOTf $(6.38 \mathrm{~g}, 4.26 \mathrm{~mL}, 38.9 \mathrm{mmol})$ was dissolved in $76 \mathrm{~mL}$ of acetonitrile in a $300 \mathrm{~mL}$ round flask. 2ethyl-2-oxazoline $(24.8 \mathrm{~g}, 25.3 \mathrm{~mL}, 250 \mathrm{mmol})$ was slowly added to the mixture at room temperature (RT). The mixture was bubbled with Ar gas for $3 \mathrm{~min}$ and then stirred at $363 \mathrm{~K}$ for 2 h. After the reaction, the mixture was cooled down to RT and then MAA (8.38 g, 8.24 mL, 97.3 mmol) and TEA (9.84 g, $13.5 \mathrm{~mL}, 97.3 \mathrm{mmol})$ were added accompanied by stirring at $343 \mathrm{~K}$ for $12 \mathrm{~h}$. After cooling down to RT, a saturated amount of $\mathrm{K}_{2} \mathrm{CO}_{3}$ was added into it and then the mixture was stirred for $24 \mathrm{~h}$. The resulting precipitate was passed through a polytetrafluoroethylene (PTFE) syringe filter with a pore-size of $0.2 \mu \mathrm{m}$ (Toyo Roshi Kaisha, Ltd., Tokyo, Japan). The solvent was removed under vacuum and the residual solid was dissolved in methanol. The solution was then precipitated in 10-fold excess of cold diethyl ether. The precipitate was then dried under vacuum for 2 days. A slightly yellow powder was obtained; yield: $40 \%$.

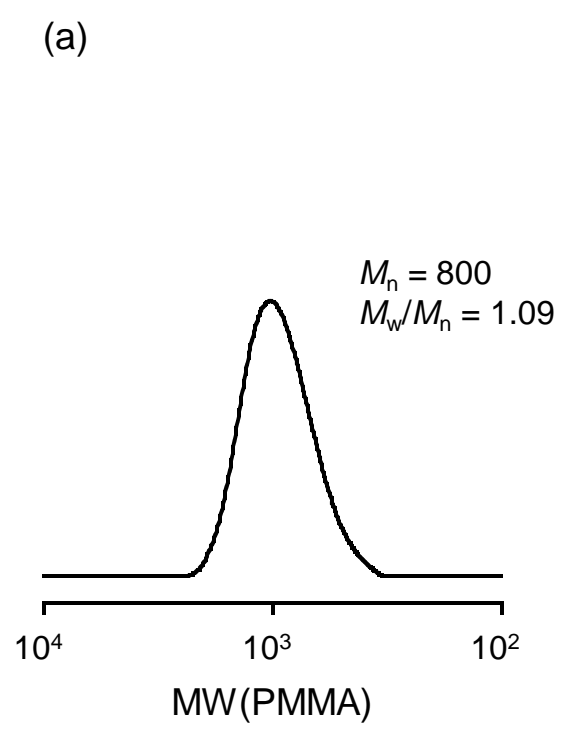

(b)
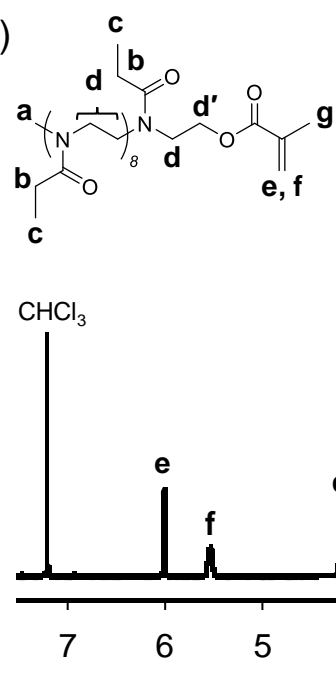

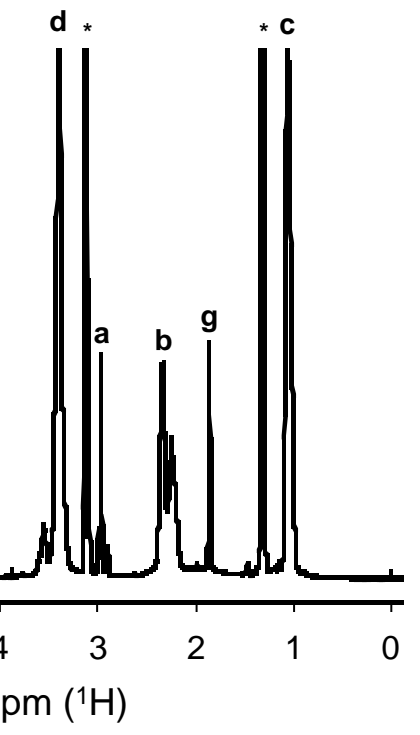

Figure S1. (a) An SEC curve for the product. The molecular weight was calibrated using PMMA standards. (b) ${ }^{1} \mathrm{H}-\mathrm{NMR}$ spectrum for the product $\left(400 \mathrm{MHz}\right.$, in $\mathrm{CDCl}_{3}$ ). Asterisks represent residual solvent.

Panel (a) of Figure S1 shows an SEC curve for the product. The curve was unimodal, and the $M_{\mathrm{n}}$ and $M_{\mathrm{w}} / M_{\mathrm{n}}$ were determined to be 800 and 1.09 , respectively. Panel (b) of Figure S1 shows a ${ }^{1} \mathrm{H}-\mathrm{NMR}$ spectrum for the product. The degree of polymerization $(n)$ was determined to be 
approximately 9 based on signals e and b corresponding to methacrylate terminal groups and methylene protons of oxazoline repeating units, respectively. This result shows the same trend as previously reported. ${ }^{\mathrm{S} 2}{ }^{1} \mathrm{H}-\mathrm{NMR}\left(400 \mathrm{MHz}, \mathrm{CDCl}_{3}\right): \delta=1.12 \mathrm{ppm}\left(\mathrm{s}, 27 \mathrm{H}, \mathrm{CH}_{3}-\mathrm{CH}_{2}-\mathrm{C}(=\mathrm{O})-\right)$, $1.91 \mathrm{ppm}\left(\mathrm{s}, 3 \mathrm{H}, \mathrm{CH}_{3}-\mathrm{C}\left(=\mathrm{CH}_{2}\right)-\right.$ ), $2.27 \sim 2.38 \mathrm{ppm}\left(\mathrm{br}, 18 \mathrm{H}, \mathrm{CH}_{3}-\mathrm{CH}_{2}-\mathrm{C}(=\mathrm{O})-\right)$ ), $2.95 \sim 3.02 \mathrm{ppm}$ (m, 3H, $\mathrm{CH}_{3}-\mathrm{N}(-\mathrm{C}=\mathrm{O})-$ ), 3.50 (br, 34H, $\left.-\mathrm{N}-\mathrm{CH}_{2}-\mathrm{CH}_{2}-\right), 4.26$ (t, $2 \mathrm{H},-\mathrm{CH}_{2}-\mathrm{CH}_{2}-\mathrm{O}-\mathrm{C}(=\mathrm{O})-$ ), $5.58 \mathrm{ppm}\left(\mathrm{s}, 1 \mathrm{H},-\mathrm{C}=\mathrm{CH}_{2}\right)$ and $6.06 \mathrm{ppm}\left(\mathrm{s}, 1 \mathrm{H},-\mathrm{C}=\mathrm{CH}_{2}\right)$.

1.4. Macroinitiator Synthesis. A PMMA macroinitiator with a Br-terminal was prepared by atom transfer radical polymerization (ATRP). ${ }^{\mathrm{S} 3}$ A Schlenk tube was baked for 5 min and filled with $\mathrm{Ar}$ gas. $\operatorname{EBiB}(0.27 \mathrm{~g}, 0.20 \mathrm{~mL}, 1.38 \mathrm{mmol})$ and MMA (27.75 g, $29.52 \mathrm{~mL}, 277.2 \mathrm{mmol})$ were dissolved in anisole $(29.70 \mathrm{~mL})$ in the Schlenk tube. Then, PMDETA $(0.24 \mathrm{~g}, 0.29 \mathrm{~mL}, 1.38$ mmol) was charged into the reaction mixture. The mixture was deoxygenated by bubbling with Ar gas for $2 \mathrm{~min}$. $\mathrm{CuBr}(198.0 \mathrm{mg}, 1.38 \mathrm{mmol})$ was added to the contents of the tube and then the mixture was bubbled with Ar gas for $2 \mathrm{~min}$. The reaction tube was placed in an oil bath at $353 \mathrm{~K}$ for $2 \mathrm{~h}$. After the reaction, the solution was diluted with toluene and then passed through an alumina column to remove the $\mathrm{Cu}$ complex. The solution was then precipitated into hexane. A white powdery product was obtained; yield: $70 \%$.

(a) 1. PMMA

2. $\mathrm{PMMA}-b-\mathrm{P}[\mathrm{O}(\mathrm{Ox}) \mathrm{MA}]$

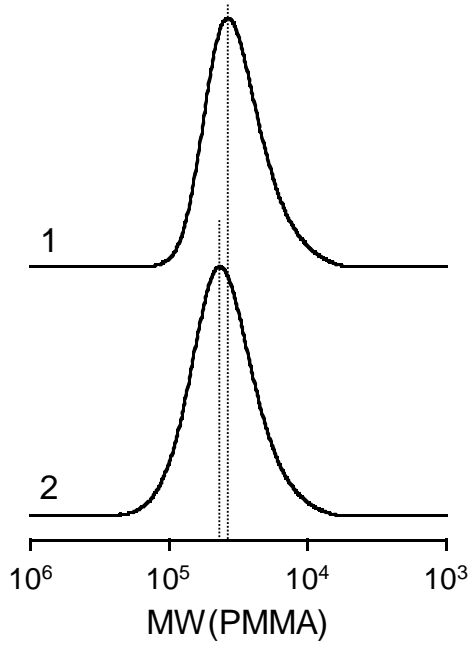

(b) 1. PMMA

2. $\mathrm{PMMA}-b-\mathrm{P}[\mathrm{O}(\mathrm{Ox}) \mathrm{MA}]$
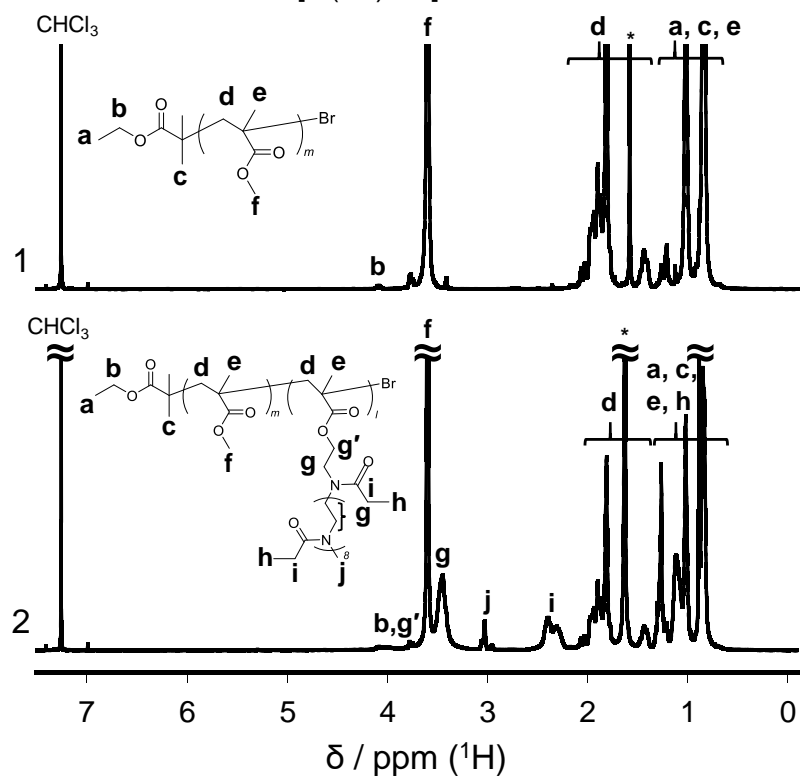

Figure S2. (a) SEC curves for (upper) PMMA and (lower) PMMA- $b-\mathrm{P}[\mathrm{O}(\mathrm{Ox}) \mathrm{MA}]$. The molecular weight was calibrated using PMMA standards. (b) ${ }^{1} \mathrm{H}-\mathrm{NMR}$ spectra for (upper) PMMA and (lower) PMMA- $b$ - $\mathrm{P}[\mathrm{O}(\mathrm{Ox}) \mathrm{MA}]\left(400 \mathrm{MHz}\right.$, in $\left.\mathrm{CDCl}_{3}\right)$. Asterisks represent the peak attributed to $\mathrm{H}_{2} \mathrm{O}$. 
The upper panel of Figure S2(a) shows an SEC curve for the product. The curve was unimodal, and the $M_{\mathrm{n}}$ and $M_{\mathrm{w}} / M_{\mathrm{n}}$ were determined to be 23,700 and 1.28 , respectively. The upper panel of Figure S2(b) shows a ${ }^{1} \mathrm{H}-\mathrm{NMR}$ spectrum for the product. The degree of polymerization $(m)$ was determined to be approximately 212 on the basis of signals $\mathbf{b}$ and $\mathbf{f}$ corresponding to the methylene group in the initiator and methoxy protons of repeating units, respectively. This result shows the same trend as previously reported. ${ }^{\mathrm{S} 3}{ }^{1} \mathrm{H}-\mathrm{NMR}\left(400 \mathrm{MHz}, \mathrm{CDCl}_{3}\right): \delta=0.81 \sim 1.26 \mathrm{ppm}(\mathrm{br}, 625 \mathrm{H}$, $\left.\mathrm{CH}_{3}-\mathrm{CH}_{2}-\mathrm{O}-(\mathrm{C}=\mathrm{O})-,-\mathrm{C}\left(\mathrm{CH}_{3}\right)_{2}-,-\mathrm{CH}_{2}-\mathrm{C}\left(\mathrm{CH}_{3}\right)-\right), 1.43 \sim 2.10$ ppm (br, 381H, $\left.-\mathrm{CH}_{2}-\mathrm{C}_{\left(\mathrm{CH}_{3}\right)-}\right)$, $3.53 \mathrm{ppm}\left(\mathrm{s}, 624 \mathrm{H},-\mathrm{C}(\mathrm{C}=\mathrm{O})-\mathrm{O}-\mathrm{CH}_{3}\right), 4.01 \mathrm{ppm}\left(\mathrm{m}, 2 \mathrm{H}, \mathrm{CH}_{3}-\mathrm{CH}_{2}-\mathrm{O}-(\mathrm{C}=\mathrm{O})-\right)$.

1.5. Block Copolymer Synthesis. A block copolymer, PMMA- $b-\mathrm{P}[\mathrm{O}(\mathrm{Ox}) \mathrm{MA}]$, was synthesized by ATRP of O(Ox)MA using the PMMA macroinitiator as follows. A Schlenk tube was baked for $5 \mathrm{~min}$ and then filled with Ar gas. PMMA (1.27 g, $0.06 \mathrm{mmol})$ and O(Ox)MA (2.97 $\mathrm{g}, 3.0 \mathrm{mmol})$ were dissolved in DMF $(4.61 \mathrm{~mL})$ in the Schlenk tube. Then, PMDETA (0.06 mmol) was added to the mixture. The solution was deoxygenated by bubbling with Ar gas for 2 min. $\mathrm{CuBr}(8.6 \mathrm{mg}, 0.06 \mathrm{mmol})$ was added to the contents of the tube and the mixture was then bubbled with Ar gas for 2 min again. The reaction tube was placed in an oil bath at $353 \mathrm{~K}$ for $30 \mathrm{~min}$. After the reaction, the mixture was precipitated into hexane several times to remove unreacted macromonomers and the precipitate was dried under vacuum. The product was dissolved into methanol and then dialyzed for 2 days to completely remove the $\mathrm{Cu}$ complex. The solution was precipitated again in hexane. After drying the precipitate under vacuum, a white powdery product was obtained; yield: $38 \%$.

The lower panel of Figure S2(a) shows an SEC curve for the product. The curve was unimodal, and the peak was shifted to the higher molecular weight side compared to the one for PMMA. The $M_{\mathrm{n}}$ and $M_{\mathrm{w}} / M_{\mathrm{n}}$ were determined to be 28,700 and 1.36, respectively. The lower panel of Figure S2(b) shows a ${ }^{1} \mathrm{H}-\mathrm{NMR}$ spectrum for the product. The degree of polymerization $(l)$ was determined to be approximately 9 on the basis of signals $\mathbf{f}$ and $\mathbf{j}$ corresponding to methoxy protons in the methyl methacrylate and methyl protons in oxazoline side chain end, respectively. ${ }^{1} \mathrm{H}-\mathrm{NMR}$ (400 $\mathrm{MHz}$, $\left.\mathrm{CDCl}_{3}\right): \delta=0.81 \sim 1.26$ ppm (br, $137 \mathrm{H}, \mathrm{CH}_{3}-\mathrm{CH}_{2}-\mathrm{O}-(\mathrm{C}=\mathrm{O})-,-\mathrm{C}\left(\mathrm{CH}_{3}\right)_{2}-,-\mathrm{CH}_{2}-\mathrm{C}\left(\mathrm{CH}_{3}\right)_{-}, \mathrm{CH}_{3}-$ $\left.\mathrm{CH}_{2}-\mathrm{C}(=\mathrm{O})-\mathrm{N}-\right), 1.43 \sim 2.10$ ppm (br, 49H, $\left.-\mathrm{CH}_{2}-\mathrm{C}\left(\mathrm{CH}_{3}\right)-\right), 2.27 \sim 2.38$ ppm (br, 16H, $\mathrm{CH}_{3}-$ $\left.\mathrm{CH}_{2}-\mathrm{C}(=\mathrm{O})-\mathrm{N}-\right), 2.95 \sim 3.05 \mathrm{ppm}\left(\mathrm{m}, 3 \mathrm{H}, \mathrm{CH}_{3}-\mathrm{N}(-\mathrm{C}=\mathrm{O})-\right), 3.44 \mathrm{ppm}(\mathrm{s}, 26 \mathrm{H},-\mathrm{N}(-\mathrm{C}(=\mathrm{O}))$ $\left.\mathrm{CH}_{2}-\mathrm{CH}_{2}-\right), 3.59 \mathrm{ppm}\left(\mathrm{s}, 81 \mathrm{H}, \mathrm{C}(\mathrm{C}=\mathrm{O})-\mathrm{O}-\mathrm{CH}_{3}\right), 3.74 \sim 4.09 \mathrm{ppm}\left(\mathrm{br}, 2 \mathrm{H}, \mathrm{CH}_{3}-\mathrm{CH}_{2}-\mathrm{O}-(\mathrm{C}=\mathrm{O})-\right.$ , $\left.\mathrm{C}(\mathrm{C}=\mathrm{O})-\mathrm{O}-\mathrm{CH}_{2}-\mathrm{CH}_{2}-\mathrm{N}-\right)$. 


\section{Bulk Characterizations of Polymers}

2.1. Differential Scanning Calorimetry (DSC). Glass transition temperature $\left(T_{\mathrm{g}}\right)$ was examined by DSC (EXSTAR6000 DSC6220, Hitachi High-Tech Science Corp., Tokyo, Japan). The measuring temperature was in the range of 213 to $423 \mathrm{~K}$ and the heating and cooling rates were $10 \mathrm{~K} \cdot \mathrm{min}^{-1}$. A polymer sample was placed in an aluminium pan and an empty aluminium pan was used as a reference.

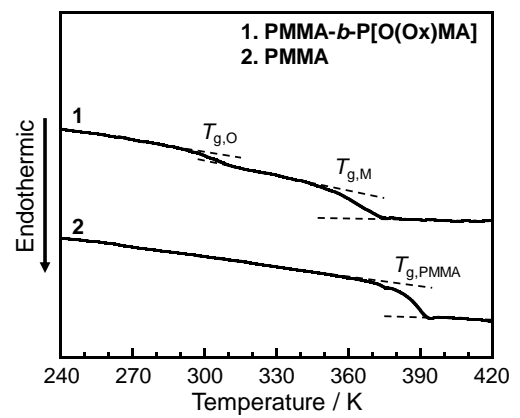

Figure S3. DSC curves for PMMA- $b-\mathrm{P}[\mathrm{O}(\mathrm{Ox}) \mathrm{MA}]$ and PMMA at the third heating scan. Dashed lines are tangents of baselines.

Figure S3 shows DSC curves at the third heating for the bulk PMMA- $b-\mathrm{P}[\mathrm{O}(\mathrm{Ox}) \mathrm{MA}]$ and PMMA samples. In the case of PMMA- $b-\mathrm{P}[\mathrm{O}(\mathrm{Ox}) \mathrm{MA}]$, two baseline shifts were observed. The middle points of the baseline shifts were assigned from the higher temperature side to the glass transition temperatures of $\mathrm{P}[\mathrm{O}(\mathrm{Ox}) \mathrm{MA}]$ - and PMMA-rich phases $\left(T_{\mathrm{g}, \mathrm{O}}\right.$ and $\left.T_{\mathrm{g}, \mathrm{M}}\right)$.

2.2. Small Angle X-ray Scattering (SAXS) Measurements. A bulk sample of PMMA- $b$ $\mathrm{P}[\mathrm{O}(\mathrm{Ox}) \mathrm{MA}]$ for SAXS measurement was prepared by a solvent casting method from a 5 wt\% chloroform solution on a PTFE substrate. After annealing at $\left(T_{\mathrm{g}, \mathrm{M}}+20\right) \mathrm{K}$, where $T_{\mathrm{g}, \mathrm{M}}$ is the bulk $T_{\mathrm{g}}$ of the PMMA rich-phase, under vacuum for $24 \mathrm{~h}$, a self-standing film was obtained. The SAXS measurement was conducted at the BL03XU beamline of SPring-8 (Hyogo, Japan). The X-ray wavelength was $0.1 \mathrm{~nm}$ and the camera distance was $2,310 \mathrm{~mm}$ calibrated with silver behenate. A PILATUS3 S 1M (DECTRIS Ltd., Baden-Däettwil, Switzerland) was used to record a twodimensional SAXS pattern.

Figure S4 shows a one-dimensional SAXS profile for the PMMA- $b$-P[O(Ox)MA] bulk sample and its Kratky plot. 

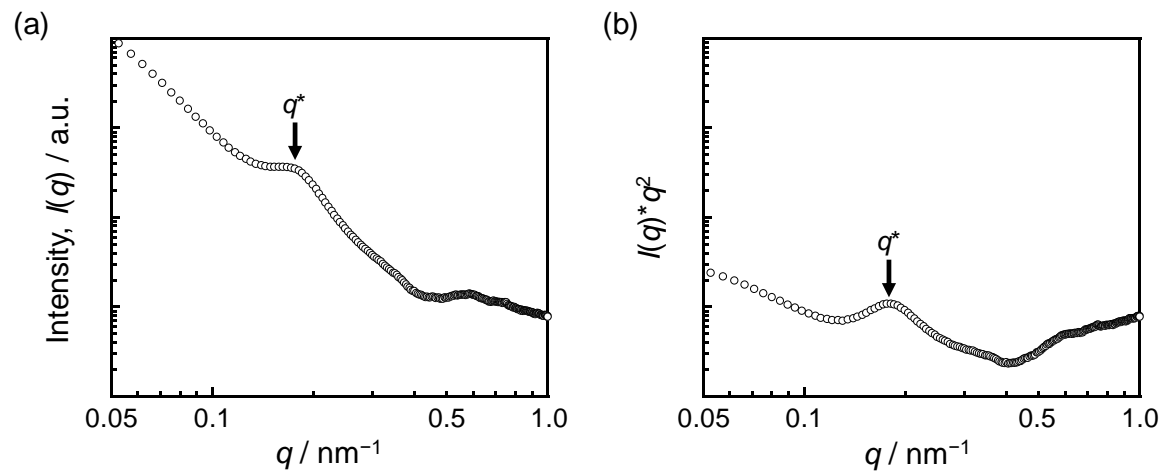

Figure S4. A one-dimensional SAXS profile for PMMA- $b-\mathrm{P}[\mathrm{O}(\mathrm{Ox}) \mathrm{MA}]$ and its Kratky plot.

\section{Thin Film Preparation}

3.1. Materials. As a solid substrate, commercially-available borosilicate glasses (Matsunami Glass Ind., Ltd., Osaka, Japan) and Si-wafers (Matsuzaki Seisakusho Co., Ltd., Shimane, Japan) were used. Chloro(decyl)dimethylsilane (> $97.0 \%$ ) was purchased from TCI. Sulfuric acid $\left(\mathrm{H}_{2} \mathrm{SO}_{4},>98 \%\right)$ was purchased from Kanto Chemical. Hydrogen peroxide (concentration (wt/wt) $>30.0 \sim 35.5 \%)$ and acetone were purchased from FUJIFILM Wako Pure Chemical Industries. Ultrapure water purified using a Milli-Q system (Merck) was used.

3.2. Spin-coating. First, solid substrates were cleaned up using a piranha solution at $363 \mathrm{~K}$ for $2 \mathrm{~h}$. After rinsing the substrates with ultrapure water and drying, chloro(decyl)dimethylsilane was vacuum-deposited onto them at a pressure of $2.0 \mathrm{kPa}$ at $\mathrm{RT}$ for $12 \mathrm{~h}$. They were then sequentially washed by toluene, acetone, and chloroform. Hydrophobization was confirmed on the basis of water contact angle measurements using a DropMaster 500 (Kyowa Interface Science Co., Ltd., Saitama, Japan). The values were approximately 100 and $103^{\circ}$, respectively, for the borosilicate and Si-wafer substrates.

A block copolymer solution was prepared by dissolving PMMA- $b-\mathrm{P}[\mathrm{O}(\mathrm{Ox}) \mathrm{MA}]$ into chloroform at $1 \mathrm{wt} \%$. Thin films of the block copolymer were prepared on the hydrophobized substrates by a spin-coating method using a 1H-D7 spin-coater (MIKASA Co., Ltd., Tokyo, Japan) at 2,000 rpm for $120 \mathrm{~s}$ at RT. These films were annealed at $\left(T_{\mathrm{g}, \mathrm{M}}+20\right) \mathrm{K}$ under vacuum for $12 \mathrm{~h}$. Thin films of PMMA were also prepared as a reference in the same manner, instead of using its 2 wt $\%$ toluene solution and the substrates without hydrophobization, and annealing at $413 \mathrm{~K}$.

\section{Evaluation of the Bio-inert Property of Films}


4.1. Cell Adhesion Tests. For cell adhesion testing, Swiss mouse embryo fibroblasts NIH3T3 (RCB1862, RIKEN BRC Cell Bank, Tsukuba, Ibaraki, Japan) were used. The block copolymer films on hydrophobized borosilicate glass substrates were firstly washed with ultrapure water three times and then immersed into water in polystyrene 24-well plates (Corning Incorporated, Corning, NY, US) for $24 \mathrm{~h}$ at RT. After removing water, the cell suspension in Dulbecco's modified Eagle's medium (DMEM) with $10 \%$ of fetal bovine serum (FBS, Life Technologies Japan, Ltd., Tokyo, Japan) at $4 \times 10^{4}$ cells $\cdot \mathrm{cm}^{-2}$ was added and incubated for $12 \mathrm{~h}$ at $310 \mathrm{~K}$. Cell adhesion behaviors were observed using a phase-contrast microscope (BZ-8100, Keyence Co., Osaka, Japan) as a function of culturing time. After the $12 \mathrm{~h}$ culturing, cells which did not adhere onto the films were removed by washing them with phosphate buffered saline (PBS, Takara Bio, Inc., Shiga, Japan) several times. The adherent cells were fixed using $2 \%(\mathrm{v} / \mathrm{v})$ of glutaraldehyde in PBS for 20 min at $277 \mathrm{~K}$. Fixed cells were stained by crystal violet $(0.01 \mathrm{wt} \%)$ dissolved in a mixed solvent composed of methanol/water $(1 / 200(\mathrm{v} / \mathrm{v}))$. The number and morphology of adherent cells were evaluated by phase-contrast microscopy.

4.2. Cell Spreading Behaviors. Spreading of fibroblasts adhered on each substrate was estimated on the basis of area of cells. Panels (a, b) of Figure S5 are the abundance of projected area of NIH3T3 fibroblasts on (a) the PMMA- $b-\mathrm{P}[\mathrm{O}(\mathrm{Ox}) \mathrm{MA}]$ and (b) reference PMMA films.
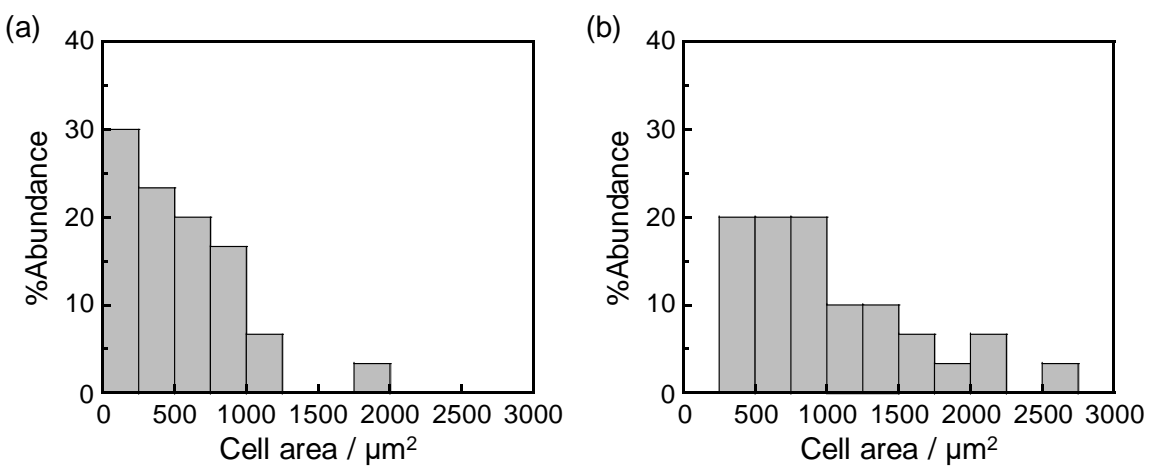

Figure S5. Abundance of projected area of NIH3T3 fibroblasts adhered on (a) PMMA- $b$-P[O(Ox)MA] and (b) PMMA films.

4.3. Protein Adsorption Tests. As a protein sample, 10\% FBS in DMEM was used. Before the test, the block copolymer films on Si-wafers were immersed into water for $24 \mathrm{~h}$ at RT, and then into the $10 \%$ FBS in DMEM for $1 \mathrm{~h}$ at $310 \mathrm{~K}$. The film surface was then gently rinsed with fresh PBS. Subsequently, adsorbed proteins were detached in $1 \mathrm{wt} \%$ of aqueous sodium dodecyl sulfate 
(SDS) solution by sonication for $20 \mathrm{~min}$ at $313 \mathrm{~K}$. The protein concentration in the SDS solution was determined using the microplate procedure of a micro-bicinchoninic acid protein assay kit (micro-BCA, Thermo Fisher Scientific K.K., Tokyo, Japan) with bovine serum albumin standard calibration. The absorbance of the sample solution at around $560 \mathrm{~nm}$ was measured using a plate reader (INFINITE 200, Tecan Japan Co., Ltd., Kanagawa, Japan). As a reference, PMMA films and polyethylene terephthalate (PET) sheets were used.

Figure S6 shows the amount of proteins adsorbed on the PMMA- $b-\mathrm{P}[\mathrm{O}(\mathrm{Ox}) \mathrm{MA}], \mathrm{PMMA}$, and PET surfaces.

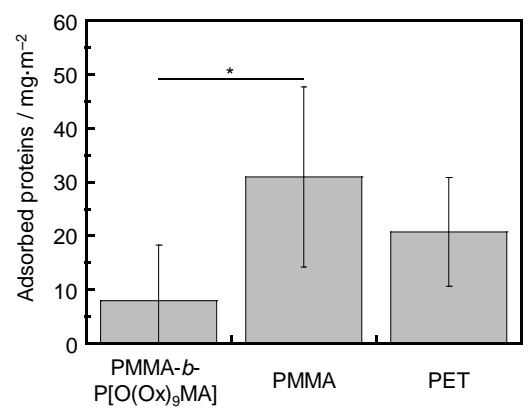

Figure S6. Total amount of adsorbed serum proteins on PMMA- $b-\mathrm{P}[\mathrm{O}(\mathrm{Ox}) \mathrm{MA}]$, PMMA, and PET surfaces assessed by micro-BCA assay. The values are expressed as mean \pm standard deviation from $n$ $=7$; ANOVA: $* p<0.01$.

\section{Surface and Interfacial Characterizations of Films}

5.1. Atomic Force Microscopy (AFM) Observations. The surface morphology of a block copolymer film on a hydrophobized Si-wafer was examined by AFM (Cypher ES, Asylum Research, an Oxford Instruments Co., Santa Barbara, CA, US) using an AC mode under air and water at $298 \mathrm{~K}$. A Si-made cantilever tip coated with Al was used. Spring constant and resonance frequency were $12 \mathrm{~N} \cdot \mathrm{m}^{-1}$ and $118 \mathrm{kHz}$ in air, respectively, and $0.09 \mathrm{~N} \cdot \mathrm{m}^{-1}$ and $26 \mathrm{kHz}$ in water. Panels (a-d) of Figure S7 represent ( $a, b)$ topological and (c, d) phase images for the (a, c) PMMA$b$ - $\mathrm{P}[\mathrm{O}(\mathrm{Ox}) \mathrm{MA}]$ and $(\mathrm{b}, \mathrm{d}) \mathrm{PMMA}$ films acquired under an air atmosphere. 

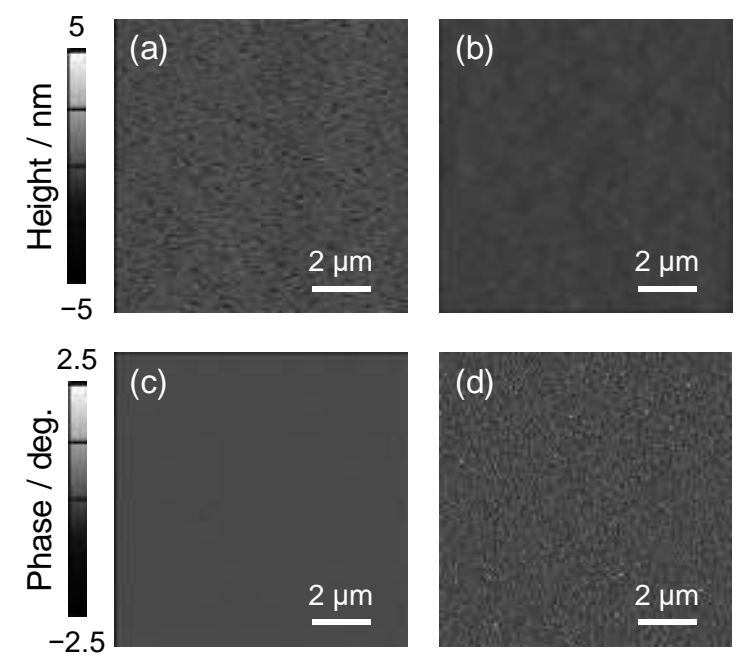

Figure S7. (a, b) AFM topological and (c, d) phase images for (a, c) PMMA-b-P[O(Ox)MA] and (b, d) PMMA films acquired in air.

Panels $(a-d)$ of Figure S8 represent $(a, b)$ topological and (c, d) phase images for the (a, c) PMMA- $b-\mathrm{P}[\mathrm{O}(\mathrm{Ox}) \mathrm{MA}]$ and $(\mathrm{b}, \mathrm{d})$ PMMA films acquired in water.
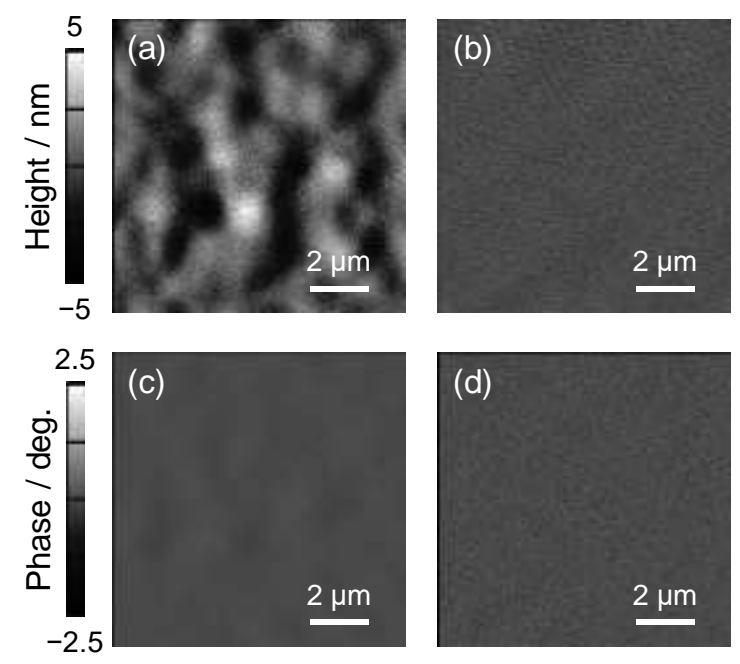

Figure S8. (a, b) AFM topological and (c, d) phase images for (a, c) PMMA- $b-\mathrm{P}[\mathrm{O}(\mathrm{Ox}) \mathrm{MA}]$ and $(\mathrm{b}, \mathrm{d})$ PMMA films acquired in water.

5.2. Static Contact Angle Measurements. Static contact angles against the films were recorded using a DropMaster 500 at RT in air. As a probe, $1 \mu \mathrm{l}$ of ultrapure water was used. In addition, static contact angle measurements using an air bubble $(2 \mu \mathrm{L})$ were performed at RT in water. 
5.3. Angular-dependent $X$-ray Photoelectron Spectroscopy (ADXPS). Surface chemical composition of dried films on Si-wafers was studied by using a PHI 5000 VersaProbe III (ULVACPHI, INC., Kanagawa, Japan) with an Al-K $\alpha$ source operated at $15 \mathrm{kV}$ and $25 \mathrm{~W}$. The take-off angle of photoelectrons $\left(\varphi_{\mathrm{e}}\right)$ ranged from 15 to $90^{\circ}$. A $\mathrm{C}_{1 \mathrm{~s}}$ peak derived from neutral carbons was calibrated to a binding energy of $285.0 \mathrm{eV}$.

The relationship between the integral intensity ratio of nitrogen to carbon $\left(I_{\mathrm{N} 1 \mathrm{~s}} / I_{\mathrm{C} 1 \mathrm{~s}}\right)$ and real analytical depth was estimated by fitting the experimental data on the basis of a model concentration profile. Photoelectrons cannot travel for a long distance in matter and the number of photoelectrons detected exponentially decays along the depth direction. Thus, the $\left(I_{\mathrm{N} 1 \mathrm{~s}} / I_{\mathrm{Cls}}\right)$ ratio at $\varphi_{\mathrm{e}}$ is given by;

$$
\frac{I_{\mathrm{N} 1 \mathrm{~s}}}{I_{\mathrm{C} 1 \mathrm{~s}}}=\frac{\int_{0}^{\infty}\left[n_{\mathrm{N}}(z) \cdot \exp \left(-z / \lambda_{\mathrm{N}} \sin \varphi_{\mathrm{e}}\right)\right] \mathrm{dz}}{\int_{0}^{\infty}\left[n_{\mathrm{C}}(z) \cdot \exp \left(-z / \lambda_{\mathrm{C}} \sin \varphi_{\mathrm{e}}\right)\right] \mathrm{dz}}
$$

where $z$ is the depth, $\lambda_{\mathrm{i}}$ and $n_{\mathrm{i}}(z)$ are the inelastic mean free path of photoelectrons and atomic fraction of component $i$, respectively.

Freeze-dried films were prepared by immersing the dried films into water at RT for $24 \mathrm{~h}$ and subsequently lyophilizing. Panels (a, b) of Figure S9 show XPS (a) $\mathrm{N}_{1 \mathrm{~s}}$ and (b) $\mathrm{C}_{1 \mathrm{~s}}$ spectra for the freeze-dried PMMA- $b-\mathrm{P}[\mathrm{O}(\mathrm{Ox}) \mathrm{MA}]$ film at different $\varphi_{\mathrm{e}} \mathrm{s}$. For comparison, the spectra for the freeze-dried PMMA film at a $\varphi_{\mathrm{e}}$ of $90^{\circ}$ are also shown. A peak corresponding to the tertiary amide nitrogen was observed in the $\mathrm{N}_{1 \mathrm{~s}}$ spectrum even at a $\varphi_{\mathrm{e}}$ of $15^{\circ}$. In addition, the intensity of peaks attributed to the amine and amide carbons in the $\mathrm{C}_{1 \mathrm{~s}}$ spectra became stronger. Since the $T_{\mathrm{g}, \mathrm{O}} \mathrm{b}$ corresponding to the $\mathrm{P}[\mathrm{O}(\mathrm{Ox}) \mathrm{MA}]$-rich phase was not so different from RT (Figure S3), the surface rearrangement from hydrophilic to hydrophobic in the film during the measurement might be possible if the surface mobility was enhanced. However, taking into account that the PMMA rich phase remained frozen even in the surface region at $\mathrm{RT},{ }^{\mathrm{S} 4}$ it seems that the extent of the surface rearrangement was not so striking if it occurred at all. 

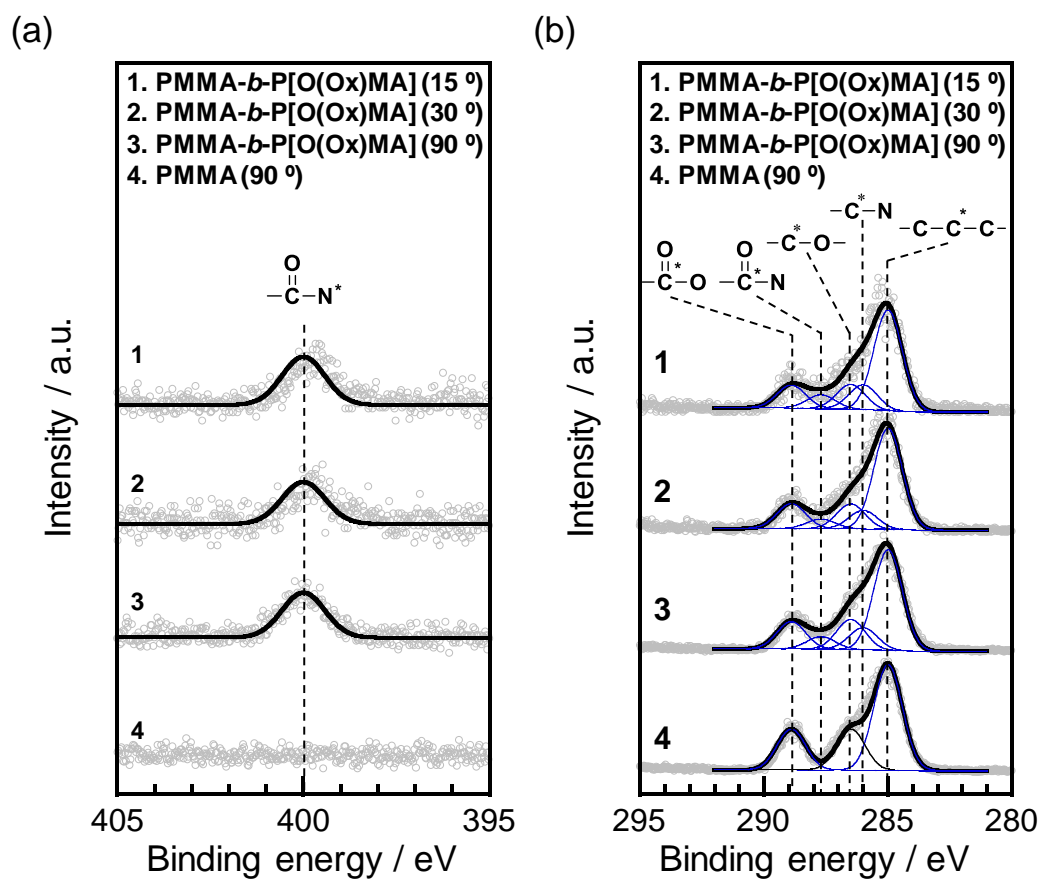

Figure S9. (a, b) XPS (a) $\mathrm{N}_{1 \mathrm{~s}}$ and (b) $\mathrm{C}_{1 \mathrm{~s}}$ spectra for the freeze-dried PMMA- $b-\mathrm{P}[\mathrm{O}(\mathrm{Ox}) \mathrm{MA}]$ and PMMA films at various $\varphi_{\mathrm{e}} \mathrm{s}$. Open symbols denote the experimental data and solid curves are fitting results. Each black curve has been decomposed to blue ones.

A simple layer model profile used for the dried film could not fit the data for the freezedried block copolymer film. Then, a model compositional profile shown below was applied to the freeze-dried film, where $\xi$ is the decay length and $n_{\mathrm{N}}{ }^{\mathrm{s}}$ and $n_{\mathrm{N}}{ }^{\mathrm{b}}$ are the nitrogen fraction at the outermost surface and in the bulk, respectively.

$$
n_{N}(z)=n_{N}^{b}+\left(n_{N}^{s}-n_{N}^{b}\right) \exp (-z / \xi)
$$

The values of $n_{\mathrm{s}}$ and $\xi$ were estimated to be 0.065 and $1.8 \mathrm{~nm}$, respectively.

5.4. Neutron Reflectivity (NR) Measurements. The density profile of the block copolymer film along the normal direction to the interface was examined by Soft Interface Analyzer (SOFIA) at the Materials and Life Science Experimental Facility (MLF), Japan Proton Accelerator Research Complex (J-PARC). The block copolymer film was prepared by a spin-coating method onto a quartz substrate with a size of $60 \times 60 \times 8 \mathrm{~mm}$ hydrophobized with chloro(decyl)dimethylsilane. First, the measurement was conducted under ambient conditions. Then, the film was contacted with deuterated water $\left(\mathrm{D}_{2} \mathrm{O}\right)$ in a Teflon-made reservoir for at least 4 hours at RT, which was enough to reach a quasi-equilibrium state. The measurement was carried out again in $\mathrm{D}_{2} \mathrm{O}$. The 
use of $\mathrm{D}_{2} \mathrm{O}$ was to enhance the contrast between the film and the aqueous phase. The incident angles of the neutron beam against the sample were $0.3,0.75$, and $1.8^{\circ}$. The reflectivity was calculated by the Motofit program provided by Dr. Andrew Nelson on the basis of a model scattering length density $(b / V)$ profile along the depth direction using the error function. The $(b / V)$ values of $\mathrm{PMMA}, \mathrm{SiO}_{2}$, and $\mathrm{D}_{2} \mathrm{O}$ were $1.04 \times 10^{-4}, 3.48 \times 10^{-4}$, and $6.36 \times 10^{-4} \mathrm{~nm}^{-2}$, respectively.

\section{REFERENCES}

S1. Tauhardt, L.; Kempe, K.; Gottschaldt, M.; Schubert, U. S. Poly(2-oxazoline) Functionalized Surfaces: From Modification to Application. Chem. Soc. Rev. 2013, 42, 7998-8011.

S2. Gieseler, D.; Jordan, R. Poly(2-oxazoline) Molecular Brushes by Grafting through of Poly(2-oxazoline)methacrylates with Aqueous ATRP. Polym. Chem. 2015, 6, 46784689.

S3. Xia, J.; Matyjaszewski, K. Controlled/“Living” Radical Polymerization. Atom Transfer Radical Polymerization Using Multidentate Amine Ligands, Macromolecules 1997, 30 , 7697-7700.

S4. Tateishi, Y.; Kai, N.; Noguchi, H.; Uosaki, K.; Nagamura, T.; Tanaka, K. Local Conformation of Poly(methyl methacrylate) at Nitrogen and Water Interfaces. Polym. Chem. 2010, 1, 303-311. 